\title{
Design of a school-based randomized trial to reduce smoking among 13 to 15 -year olds, the X:IT study
}

Anette Andersen ${ }^{1 *}$, Lotus Sofie Bast ${ }^{1}$, Lene Winther Ringgaard ${ }^{2}$, Louise Wohllebe ${ }^{2}$, Poul Dengsøe Jensen ${ }^{2}$, Maria Svendsen ${ }^{1}$, Peter Dalum ${ }^{2}$ and Pernille Due ${ }^{1}$

\begin{abstract}
Background: Adolescent smoking is still highly prevalent in Denmark. One in four 13-year olds indicates that they have tried to smoke, and one in four 15-year olds answer that they smoke regularly. Smoking is more prevalent in socioeconomically disadvantaged populations in Denmark as well as in most Western countries. Previous school-based programs to prevent smoking have shown contrasting results internationally. In Denmark, previous programs have shown limited or no effect. This indicates a need for developing a well-designed, comprehensive, and multi-component intervention aimed at Danish schools with careful implementation and thorough evaluation. This paper describes X:IT, a study including 1) the development of a 3-year school-based multi-component intervention and 2) the randomized trial investigating the effect of the intervention. The study aims at reducing the prevalence of smoking among 13 to 15 -year olds by $25 \%$.
\end{abstract}

Methods/Design: The X:IT study is based on the Theory of Triadic Influences. The theory organizes factors influencing adolescent smoking into three streams: cultural environment, social situation, and personal factors. We added a fourth stream, the community aspects. The X:IT program comprises three main components: 1) smoke-free school premises, 2) parental involvement including smoke-free dialogues and smoke-free contracts between students and parents, and 3) a curricular component. The study encompasses process- and effect-evaluations as well as health economic analyses. Ninety-four schools in 17 municipalities were randomly allocated to the intervention (51 schools) or control (43 schools) group. At baseline in September 2010, 4,468 year 7 students were eligible of which 4,167 answered the baseline questionnaire (response rate $=93.3 \%$ ).

Discussion: The X:IT study is a large, randomized controlled trial evaluating the effect of an intervention, based on components proven to be efficient in other Nordic settings. The X:IT study directs students, their parents, and smoking prevention policies at the schools. These elements have proven to be effective tools in preventing smoking among adolescents. Program implementation is thoroughly evaluated to be able to add to the current knowledge of the importance of implementation. X:IT creates the basis for thorough effect and process evaluation, focusing on various social groups.

Trial registration: Current Controlled Trials ISRCTN77415416.

Keywords: Smoking prevention, Adolescence, School-based, Parental involvement, Randomized trial, Design, Intervention

\footnotetext{
* Correspondence: anan@niph.dk

${ }^{1}$ National Institute of Public Health, University of Southern Denmark, Øster

Farimagsgade 5A, 1353 Copenhagen, Denmark

Full list of author information is available at the end of the article
} 


\section{Background}

Smoking is still by far the most health-compromising risk behavior. Smoking is, in Denmark, the cause of every fourth death annually and although smokers live shorter lives, they may expect more years with long-standing diseases [1]. The prevalence of adolescent smokers in Denmark has been decreasing over the past two decades. However, since 2006, the trend seems to have leveled out, especially among boys $[2,3]$. In Denmark, one fourth of the 13-year olds and almost half of the 15-year olds have tried to smoke. Eight percent of the 13-year olds smoke on a regular basis. Twenty-three percent of the 15-yearold boys and $24 \%$ of the girls report that they smoke on a daily, weekly, or monthly basis [4]. Smoking is more prevalent among Danish adolescents from lower socioeconomic backgrounds (SEP) $[5,6]$. This socioeconomic pattern is recognized in most Western countries [7].

Danish legislative initiatives in 2001 and 2004 seem to have lowered the prevalence of young smokers. In 2001, a national law concerning smoke-free environments banned student's smoking in Danish public schools. This law was revised in 2007 to include the teachers, who were no longer allowed to smoke on school premises unless in special smoking areas with restricted access. In 2004, the first age limit for buying cigarettes was introduced at age 16. The prevalence of regular smoking among girls was almost halved during the years 1998 to 2006; among 13-year olds from 15\% to 7\%; and among 15 -year olds from $38 \%$ to $25 \%$. Among 13-year-old boys, the prevalence of regular smoking fluctuated around $11 \%$, but among 15 -year olds it decreased from $31 \%$ to $27 \%$ [8]. From 2006 to 2010, the prevalence of 13- and 15 -year-old smokers in Denmark did not change, although the age limit for buying cigarettes was raised to 18 years in 2008 [4]. Thus, to further reduce smoking prevalence among young Danes, it is necessary to supplement current legislative initiatives with other means of intervention.

School-based programs for smoking prevention have been widely used internationally, but evaluations have shown contrasting results [9]. Comprehensive strategies using a number of extensive components are generally more effective than information-based interventions only, which have shown limited or no effect [10-12]. Between 1998 and 2001, Denmark participated in the international intervention study "The European Smoking Prevention Framework Approach" (ESFA). ESFA was a communitybased, randomized controlled trial, which targeted four intervention levels, i.e. adolescents in school, school policies, parents, and the community. Overall, ESFA showed a small but significant effect with a $6 \%$ lower increase in weekly smokers in the experimental group over a 30 month period. ESFA showed the strongest effect in Portugal and smaller effects in Finland and Spain.
Unfortunately, ESFA did not decrease adolescent smoking in Denmark, the Netherlands, or the UK [13]. Two nation-based interventions in Denmark, "Smoke-free classes" and "Tackling" did not show to have an effect either [14]. A well designed comprehensive, multi-component intervention approach, with careful implementation leading to high engagement among participants, and followed by thorough implementation and evaluation, is therefore required in Denmark.

We developed a school-based, multi-component program for the prevention of adolescent smoking, X:IT. The aims of this article are: 1) to describe the development of the X:IT intervention, 2) to examine, to which degree randomization of the trial resulted in comparable groups of intervention and control schools, and 3) to describe the evaluation of the intervention.

\section{Methods/Design}

The overall aim of the X:IT study was to develop, implement, and evaluate an intervention, easily applicable and sustainable in schools and municipalities.

\section{The theoretical model}

The Theory of Triadic Influences (TTI) encompasses the general cultural environment in which adolescents mature, the more immediate social situation in which they find themselves, and intrapersonal differences among adolescents. These three streams of influence work through different mediating variables, e.g. attitudes, normative beliefs, and self-efficacy. They finally affect the outcomes, smoking intentions, and smoking behaviour [15]. TTI was developed as a theoretical framework to capture influences on experimental tobacco and alcohol use. It has found use in previous studies of smoking in adolescence [16-18] and in studies of other health behaviors, e.g. increased fruit and vegetable intake in the "Pro Children project" [19]. As was the case in the "Pro Children project," we separated the cultural environment stream into two streams of influence: attitudinal influences, which capture the close cultural environment of the adolescents; and environmental influences, which capture the structural aspects that are known to influence adolescent smoking.

Using TTI and a social ecological approach [20], we developed the conceptual model for the X:IT study (Figure 1).

The Intervention Mapping guidelines were used to inspire the development of the study [21]. Reporting of this study's findings will comply with the CONSORT statement for cluster randomized controlled trials $[22,23]$.

\section{Development of the intervention}

First, we conducted a thorough literature review on determinants of smoking initiation to uncover determinants at different levels. Second, we conducted a comprehensive search of the literature to review existing interventions 


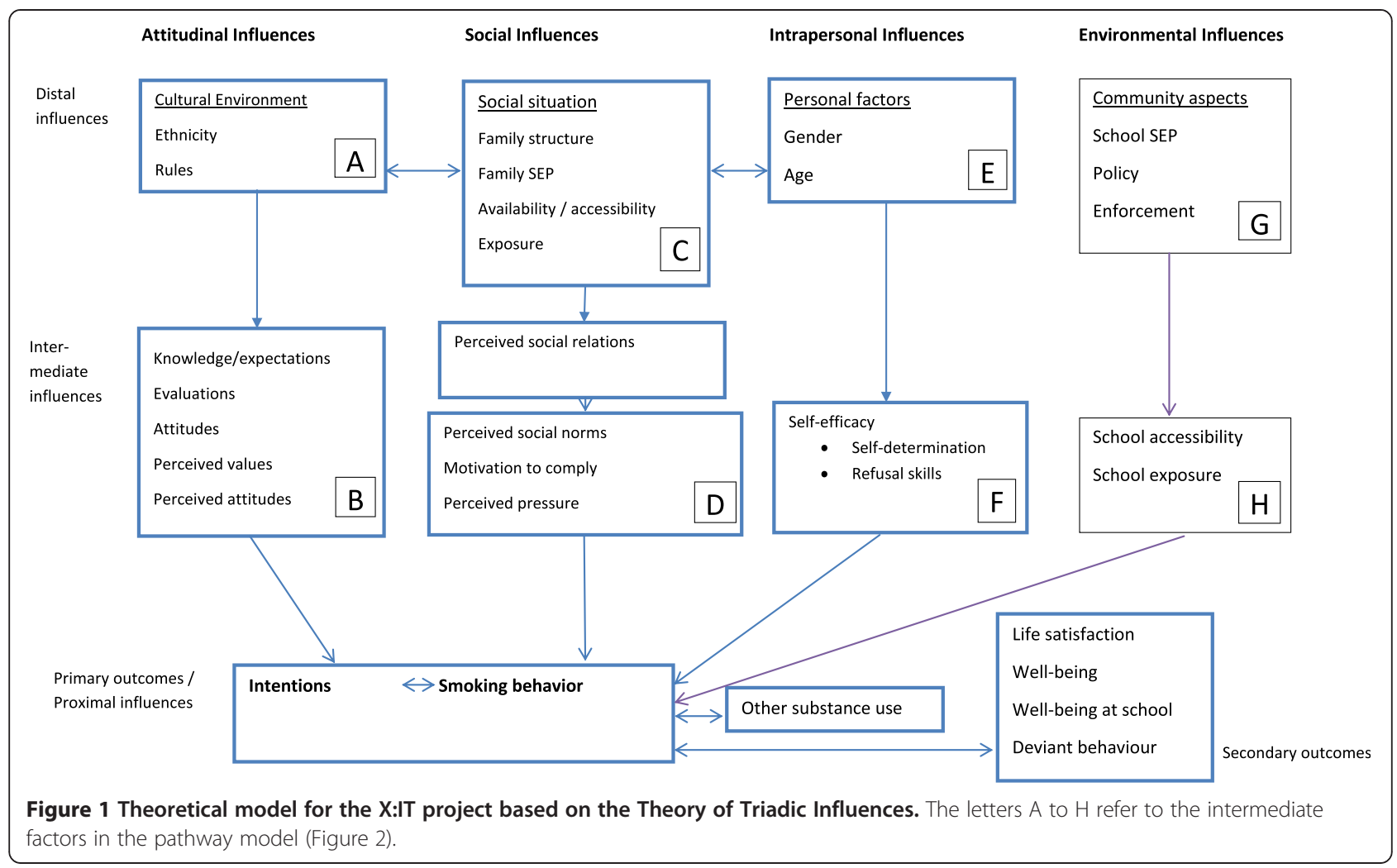

shown to be effective. The search led us to focus on the Norwegian program "Fri" [24] and the Swedish program "Tobacco Free Duo" [25]. Since these countries have a culture resembling the Danish their positive experiences might be transferable to a Danish context. Overall, it was decided that X:IT should include three main intervention components: 1) completely smoke-free school premises; 2) parental involvement comprising two dimensions: a) a smoke-free contract between the student and an adult person, preferably a parent, b) smoke-free dialogues; and 3) a smoke-free curriculum based on self-efficacy training and outcome expectancies.

\section{Intervention components}

\section{Smoke-free school premises}

Danish legislation against smoking on school premises (before August 2012) meant that students and teachers were not allowed to smoke on school premises during school hours. However, schools were allowed to have an indoor smoking area for teachers, provided it was not located nearby students.

The association between teachers smoking during school hours and students smoking has been examined in the literature. A Danish study showed that students exposed to teachers' smoking on the outdoor school premises were more likely to smoke daily, taking relevant confounders into account [26]. Recent studies from the US showed that higher levels of perceived enforcement of anti-smoking policy at the school level were inversely associated with the prevalence of the past-30-day smoking behaviors among students, independent of individual-level predictors $[27,28]$. Based on these observations, the X:IT intervention was defined to require smoke-free premises indoors as well as outdoors. This requirement applied to both students and teachers throughout school hours. Schools were encouraged to plan enforcement strategies.

After pilot testing, it became obvious that in order to include a sufficient number of schools, it was necessary to allow some schools to make an exception from the intervention requirement of totally smoke-free school premises. The revised schedule accepted schools with outdoor school premises to be used for teachers smoking. However, teacher smoking during school hours was required to be invisible to students ( 22 of 43 control schools and 26 of 51 intervention schools had smoking areas for teachers). For students, schools were still required to be completely smoke-free on all school premises during school hours.

\section{Parental involvement}

Both the Norwegian study 'FRI' and the Swedish study 'Tobacco Free Duo' have successfully used smoke-free contracts between students and parents. In the Swedish study, this component separately appeared to reduce smoking prevalence by almost 50\% [24]. By signing a smoke-free contract, the adolescent promises to stay 
smoke free for the next year. Signing the contract is a manifestation of an active choice of non-smoking. One of the parents or another adult co-signs the contract. With the contract, the signatory promises to conduct a smoke-free dialogue with the adolescent and to support the adolescent's choice of staying smoke-free. Having a smoke-free dialogue involves that the parent clearly takes exception to adolescent smoking, and that the parent asks the child about thoughts about and experiences with tobacco. This kind of constructive communication has shown to be effective [29]. The adolescents are motivated to make a personal choice, and engaging the parents signals a clear opposition to adolescent smoking. Smoke-free contracts and smoke-free dialogues are part of the X:IT intervention. Students who remained smokefree for one year were able to win a prize, sponsored by the municipalities.

\section{Smoke-free curriculum}

A Cochrane review concluded that there is no strong evidence for the effect of school-based programs that provide information-giving curriculum components only. On the other hand, an information-giving curriculum incorporated in multi-modal programs seem to be successful [9]. Programs based on social influence approaches which included: 1) correcting adolescents' perceptive overestimation of the smoking prevalence; 2) recognizing highrisk situations, 3) increasing awareness of media, peer, and family influences; 4) teaching and practicing refusal skills; and 5) making public commitments not to smoke, were more effective $[9,30]$. The teaching program for the X:IT intervention was developed based on the above awareness. The program includes eight lessons a year for three years holding detailed study guidelines for each educational year. The teachers can choose methods of teaching as well as supplementary exercises and materials.

The actual educational material, "Gå op I røg" (Up in Smoke), was developed in conjunction with scholars who had educational experience. The material targets students, 13 to 15 years of age. It is designed to be used in diverse subjects such as science, humanities, and social science. Goals in the National Executive Order of Education can be fulfilled by using the material. The material is organized as two books for pupils and two books for teachers.

A model of expected pathways for effects of the X:IT program is provided in Figure 2. The figure shows influences of each intervention component and the intermediate individual and contextual factors they are expected to influence on the way to affecting the outcome.

Other materials and tools were developed for 1) municipalities and schools. These materials and tools included background information and scientific documentation, information pamphlets concerning the study and the teaching material, detailed guidelines, and check lists. Furthermore, templates for letters, graphic tools, e.g. logos for mails and letters, newsletters, and a Power Point presentation eligible for introducing the study at parent-meetings at the schools. 2) for parents: smoke-free contracts, pamphlets, and a homepage, www.roegfridialog.dk.

All materials and information are available at the X:IT homepage, www.xit-web.dk. An overview of all intervention components of the X:IT study is presented in Table 1.

\section{Pilot testing}

In the autumn of 2008, staff in charge of health promotion at the 98 municipalities in Denmark received an invitation to participate in a pre-conference about the X:IT study. The aim of this workshop was to inform municipalities about the study and to receive feed-back on an early draft of the design of the intervention. One hundred and twelve individuals from 47 municipalities participated. Discussions at the conference led to several changes in the program. One of the early main components -local non-smoking clubs known from the Swedish program "SMART" - was considered ethically inappropriate in a Danish setting and was left out of the intervention.

The intervention was pilot tested in two municipalities and ten schools in one of the municipalities. Qualitative data were collected from project coordinators in the municipalities, from headteachers, teachers, pupils and parents. Results from the pilot tests showed an overall satisfaction with the program. As described earlier, the pilot test demonstrated a need to relax the very strict nonsmoking school policies that were part of the initial program. In the pilot test, the educational material was described to be of high quality, easy to use, and inviting. As schools are generally pressed for time, the material was designed to be part of the mandatory curriculum, and the pilot test emphasized this to be an advantage.

Study coordinators at the municipalities and headteachers at the schools emphasized that economic resources and precise indication of expected time expenditure were important for their acceptance of the study. Also, they found it essential to have centralized management of the study at the municipal level and to have local coordinators at schools and at municipalities. Coordinators, teachers, and parents emphasized that detailed guidelines for all tasks would be useful. Furthermore, they stressed the need of reminders about the study during the school year. This was included in the final program as newsletters.

Lottery prizes in relation to the contracts were appreciated as important motivational factors for the students. In the final program, the prizes were prioritized accordingly.

In the spring 2010, baseline questionnaires for students were pilot tested in five year 7 classes at two socioeconomically diverse schools in the municipality of Aalborg. The students answered the questionnaires and 
focus group interviews were subsequently conducted with some of the pupils. Only minor revisions were necessary after testing among students.

A newsletter was provided twice a year for municipalities, intervention and control schools taking part in the study. Updates on materials and guidelines are sent out via emails and are available on the X:IT webpage.

\section{Evaluation \\ Design}

The X:IT study will be evaluated by means of effect, process, and health economic evaluations. We used a cluster randomized controlled design for the effect evaluation of the intervention.

\section{Setting}

Denmark has 98 municipalities with an average 50,000 to 60,000 inhabitants. According to Eurostat, Denmark is one of the least urbanized countries in Europe with only $22 \%$ of the population living in urban regions compared to $41 \%$ on average in all European countries (European Commission http://epp.eurostatec.europa.eu/cache/ITY_PUBLIC/1-30032012BP/EN/1-30032012-BP-EN.PDF). There would be around one school pr. 5,000 inhabitants in a municipality. The Danish public school consists of year 0 (preschool class) and year 1-9. All 10 years are mandatory. The Danish children start school the year they turn 6 . Children who start together in the same class at year 0 will belong to the same class/group of children through all ten years of schooling. There is a limit of 28 children per class. Schools with year 7-9 students have 2-4 parallel tracks. There is no grouping by ability in the Danish schools i.e. that all children have joint lecturing. $85 \%$ of all Danish children attend the public school and the schools are area-based, which means that they have a wide socioeconomic composition.

\section{Population}

Seventeen municipalities of the 98 invited agreed to participate in the study. All selected a municipal coordinator of the study. The municipalities in the X:IT study varies between 35,000 and 295,000 inhabitants, and included five of the ten largest municipalities in Denmark. They are spread all over Denmark.

According to the study plan, municipal coordinators were to address and recruit schools from their municipality. However, due to a challenging recruitment process, research staff had to assist the coordinators. Within the 17 municipalities, 97 of 302 eligible schools agreed to participate in the study and all of these selected a school coordinator for the study (Figure 3).

\section{Randomization}

Randomization of schools was stratified within the $17 \mathrm{mu}$ nicipalities. Schools recruited were randomized to either the control or intervention group by drawing lots. Fiftythree schools were randomized to intervention schools and 44 to control schools. Three schools withdrew after randomization, leaving 51 interventions schools and 43 control schools in the final study (Figure 3).

\section{Implementation}

Implementation was launched by one-day kick-off workshops for school head teachers, school coordinators, and municipal coordinators in the spring of 2010. Staff from the Danish Cancer Society, who developed the intervention and the teaching material, led the meetings. The kick-off workshop included a thorough presentation of the intervention and the study, its aim and background, an introduction to the teaching material, and an overview of the evaluation of the study. During the workshop, participants were supposed to make suggestions on how to implement the three components of the study. A folder with all background information and curriculum schedules for each of the eight mandatory classes and optional classes was given to the participants. 
Table 1 The intervention components of the X:IT study

\begin{tabular}{|c|c|c|c|c|}
\hline Setting/arena & Intervention component & Timing & Determinant & Learning objective \\
\hline \multirow[t]{6}{*}{ Class } & \multirow[t]{6}{*}{ Smoke free curriculum } & \multirow[t]{6}{*}{$\begin{array}{l}\text { At least } 8 \text { lessons a year in year } 7,8 \text {, } \\
\text { and } 9\end{array}$} & \multirow[t]{3}{*}{ Knowledge } & $\begin{array}{l}\text { - Increase awareness of long- and short-term } \\
\text { risks of smoking }\end{array}$ \\
\hline & & & & - Reduce 'majority misunderstanding' \\
\hline & & & & $\begin{array}{l}\text { - Increase awareness of smoking inducing } \\
\text { mechanism in the society }\end{array}$ \\
\hline & & & Self-efficacy & $\begin{array}{l}\text { - Increase individual ability to resist temptation } \\
\text { to smoke }\end{array}$ \\
\hline & & & \multirow[t]{2}{*}{ Perceived norms and attitudes } & - Increase identification with non-smokers \\
\hline & & & & - Contribute to creating smoke free environments \\
\hline \multirow[t]{7}{*}{ Home/parents } & \multirow[t]{6}{*}{ Smoke free contract } & \multirow[t]{6}{*}{ Start of every school term } & \multirow[t]{2}{*}{ Parental attitudes } & - Create supportive smoke free environment \\
\hline & & & & - Signal opposition to adolescent smoking \\
\hline & & & Availability & - Reduce availability of cigarettes \\
\hline & & & Exposure & - Reduce exposure to smoking \\
\hline & & & \multirow[t]{2}{*}{ Perceived norms and attitudes } & - Increase identification with non-smokers \\
\hline & & & & - Contribute to create smoke free environments \\
\hline & Leaflet for parents & Start of every school term & & $\begin{array}{l}\text { - Inform about the study, especially the smoke } \\
\text { free contract }\end{array}$ \\
\hline \multirow[t]{4}{*}{ School } & \multirow[t]{3}{*}{ Smoke free school } & \multirow[t]{3}{*}{ Throughout study } & Exposure & - Remove exposure to smoking \\
\hline & & & \multirow[t]{3}{*}{ Perceived norms and attitudes } & - Increase identification with nonsmokers \\
\hline & & & & - Contribute to creating smoke free environments \\
\hline & Parent-teacher meetings & Start of every school term & & $\begin{array}{l}\text { - Present study information, especially the smoke } \\
\text { free contract }\end{array}$ \\
\hline \multirow[t]{8}{*}{ School and municipality } & $\begin{array}{l}\text { Kick-off meetings for coordinators at } \\
\text { intervention schools and in municipalities }\end{array}$ & Before start of study period, spring 2010 & & - Inform about background and methods in the study \\
\hline & \multirow[t]{3}{*}{$\begin{array}{l}1 \text { day workshops for coordinators at } \\
\text { intervention schools and in municipalities }\end{array}$} & \multirow[t]{3}{*}{ Spring 2011, 2012 and 2013} & & $\begin{array}{l}\text { - Share experiences and receive inspiration to solve } \\
\text { problems }\end{array}$ \\
\hline & & & & - Get inspired to new teaching methods \\
\hline & & & & - Secure sustainability of the study \\
\hline & \multirow{2}{*}{$\begin{array}{l}\text { Newsletters for intervention- and control } \\
\text { schools, and municipalities }\end{array}$} & \multirow[t]{2}{*}{ 3-4 each year throughout study } & & - Inform about study \\
\hline & & & & - Secure sustainability of the study \\
\hline & \multirow[t]{2}{*}{ Study reports for each school and municipality } & \multirow[t]{2}{*}{ Spring 2011, 2012 and 2013} & & - Inform about prevalences from the study \\
\hline & & & & - Secure sustainability of the study \\
\hline Municipality & Sponsoring smoke free student prize & Spring 2011, 2012 and 2013 & & - Smoke free competition \\
\hline
\end{tabular}




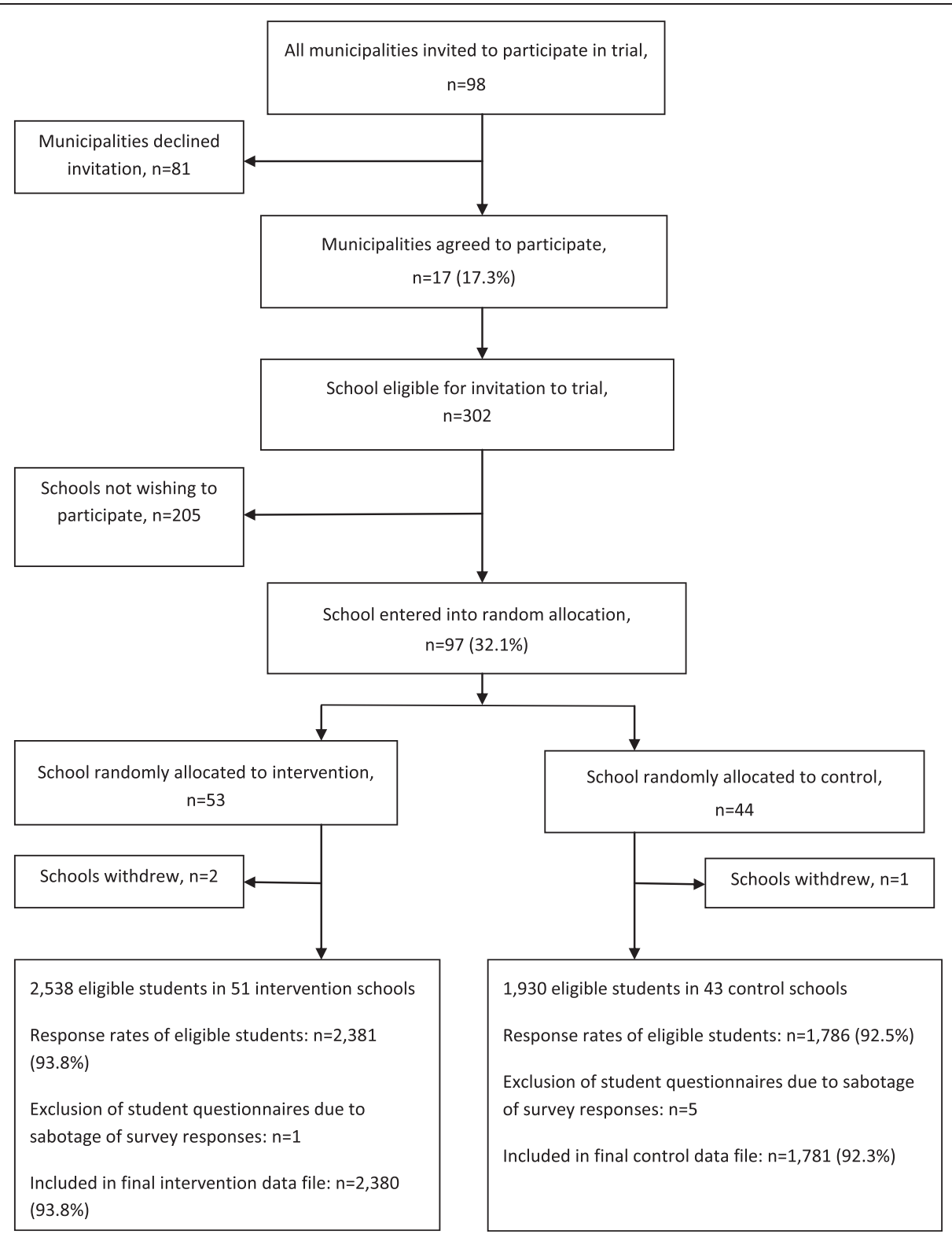

Figure 3 Flow diagram of recruitment, randomization, and participation of municipalities, schools and students at baseline in the X:IT study.

Parents were informed about the study and their involvement in two ways: 1) at meetings for parents at each school at the beginning of the school year, 2) as written information, a letter and a pamphlet, which the students brought home.

At school, students were informed about the study by the school coordinator and they received written information designed specifically for them.

\section{Effect evaluation}

\section{Instruments}

Measures used in the student questionnaires were mainly selected from existing smoking surveys: "Control of
Adolescent Smoking" (CAS) [26,31,32], “The European Smoking Prevention Framework" (ESFA) [33,34], “Be smokeFree” (FRI) [25], “Adolescents' lifestyle and daily living" (MULD) [2], European School Survey Project on Alcohol, and Other Drugs (ESPAD http://www.espad.org/), as well as the HBSC study [35]. For lack of suitable measures, new measures were developed for the X:IT study, specifically. Identical questionnaires for baseline and first (1FU), second (2FU), and third (3FU) follow-up surveys were used, although relevant evaluation questions were added to the follow-up versions. 


\section{Primary outcomes}

Frequency of student smoking was measured by the selfreported question: "How often do you smoke at present?" (every day; not every day, but every week; not every week, but every month; more seldom than every month; never) (ESFA) [36]. Furthermore, questions of intentions to smoke (CAS), having smoked ever (HBSC), number of cigarettes (MULD), and age at smoking initiation (HBSC) were included in the student questionnaires.

\section{Distal attitudinal influences}

Ethnicity was measured as student's and parents' country of origin and language spoken at home (HBSC) [37]. Smoking rules at home were measured by permission to smoke at home or not (X:IT).

\section{Intermediate attitudinal influences}

Knowledge about smoking was measured by a selection of yes/no questions about topics mentioned in the educational material (X:IT). Evaluations of consequences were measured by motives to stay smoke-free (FRI) and perceived consequences of smoking: risk, less nervousness or loneliness, ability to stay slim (ESFA). Attitudes were measured as attitudes towards rules against smoking at school and at home (CAS), and attitudes towards peers who smoke (X:IT). Parental perception of the values of the X:IT study was measured (X:IT). Parental attitudes were measured as parents' active engagement in their child's smoking behaviour (X:IT).

\section{Distal social influences}

Family structure was measured by asking whom the students live with (Pro Children). Family socioeconomic position (SEP) was measured by parental occupation (HBSC). Availability/accessibility to cigarettes from parents and peers was measured as whether cigarettes were available in the home. Also, whether the student had ever had or bought cigarettes from their parents, peers, or others (ESPAD/X:IT). Exposure to parents' and peers' smoking was measured by frequency measures and by asking where parents and peers smoke (HBSC).

\section{Intermediate social influences}

Social relations to parents and peers were measured as frequency of physical and electronic contacts as well as number and quality of confident relations (HBSC). Social norms of parents and peers were measured, as well as the student's motivation to comply with parents' and peers' norms (CAS).

\section{Distal intrapersonal influences}

Personal factors included gender and age.

\section{Intermediate intrapersonal influences}

Self-efficacy for smoking was measured by questions about ability to resist smoking if friends smoke, ability to explain to others if not wanting to smoke, and ability to reject smoking if offered a cigarette [38].

\section{Distal environmental influences}

School level SEP was measured using a question to the school coordinator regarding the wealth of the school district (HBSC). Smoking policy in the municipality and at school was measured by questions for municipal and school coordinators. Enforcement of rules at school was measured by questions for students and school coordinators (CAS).

\section{Intermediate environmental influences}

Availability/accessibility of tobacco at school was measured by the possibility of buying cigarettes close to the school (HBSC). Exposure at school was measured as frequency of observed smoking among teachers and other students (CAS). Both students and school coordinators answered these questions.

\section{Secondary outcomes}

Additional substance use, drinking alcohol, and smoking marijuana, were measured as ever use, frequency, and initiation by student self-reports (HBSC). Life satisfaction was measured by the Cantrill ladder. Well-being was measured by questions about well-being at school and in the school class, and by questions on bullying, loneliness, and frequency of symptoms (HBSC).

\section{Process evaluation}

Questions used for process evaluation were added to the student and to the teacher questionnaires. Questions were also added to the school and municipal coordinator questionnaires at $1 \mathrm{FU}, 2 \mathrm{FU}$, and 3FU. A qualitative process evaluation was conducted where quantitative evaluation was considered to be insufficient: for the recruitment of municipalities and schools into the study (conducted spring 2010), for the implementation of the smoke-free curriculum (conducted spring 2012), and for the implementation of the smoke-free dialogue (conducted autumn 2012).

The process evaluation of the X:IT study was structured according to Steckler \& Linnans' model [39]. For the overall study and for each of the three intervention components measures of 'context,' 'reach', 'dose delivered,' 'dose received,' 'fidelity, 'implementation', and 'recruitment' were considered, developed, and measured if considered relevant. Process data were obtained from students, teachers, and coordinators at schools and in municipalities.

\section{Smoke free school premises}

Context was measured by questions on smoking policy at the schools and answered by students and school 
Table 2 Data collection of the X:IT study - timeline, instrument and source of data

\begin{tabular}{|c|c|c|c|c|c|c|c|}
\hline & Baseline & Intervention & Follow-up 1 & Intervention & Follow-up 2 & Intervention & Follow-up 3 \\
\hline & September 2010 & & June 2011 & & June 2012 & & May 2013 \\
\hline Interventions schools & $\begin{array}{l}\text { Questionnaires. Students } \\
\text { start year } 7 n=2,380\end{array}$ & & $\begin{array}{l}\text { Questionnaires. Students } \\
\text { end year } 7 n=2,202\end{array}$ & $\begin{array}{l}\text { Observation and interviews } \\
\text { about implementation of } \\
\text { curriculum }\end{array}$ & $\begin{array}{l}\text { Questionnaires. Students } \\
\text { end year } 8 n=1,748\end{array}$ & & $\begin{array}{l}\text { Questionnaires. } \\
\text { Students end year } \\
9 n=777\end{array}$ \\
\hline Control schools & $\begin{array}{l}\text { Questionnaires. Students } \\
\text { start year } 7 n=1,781\end{array}$ & & $\begin{array}{l}\text { Questionnaires. Students } \\
\text { end year } 7 n=1,562\end{array}$ & & $\begin{array}{l}\text { Questionnaires. Students } \\
\text { end year } 8 n=1,521\end{array}$ & & $\begin{array}{l}\text { Questionnaires. } \\
\text { Students end year } \\
9 n=639\end{array}$ \\
\hline Students and parents & & $\begin{array}{l}\text { Smoke free contracts } \\
\mathrm{n}=3,046\end{array}$ & & $\begin{array}{l}\text { Smoke free contracts } \\
n=1,731\end{array}$ & & $\begin{array}{l}\text { Smoke free contracts } \\
\mathrm{n}=1,089\end{array}$ & \\
\hline $\begin{array}{l}\text { Study coordinator at } \\
\text { schools }\end{array}$ & & & Questionnaires $n=92$ & & Questionnaires $n=78$ & & $\begin{array}{l}\text { Questionnaires } \\
n=61\end{array}$ \\
\hline $\begin{array}{l}\text { Study coordinator in } \\
\text { municipalities }\end{array}$ & & & Questionnaires $n=17$ & & & & $\begin{array}{l}\text { Questionnaires } \\
\mathrm{n}=17\end{array}$ \\
\hline $\begin{array}{l}\text { Teachers at intervention } \\
\text { schools }\end{array}$ & & & Questionnaires & $\begin{array}{l}\text { Interviews about } \\
\text { implementation } \\
\text { of curriculum }\end{array}$ & Questionnaires & & Questionnaires \\
\hline
\end{tabular}


coordinators. The intervention was school-based and therefore, the reach included all students attending year 7 to 9 . The dose received was measured by the degree to which the schools responded to the rules. These questions were answered by both students and school coordinators.

\section{Smoke free contracts}

Context was measured by questions regarding parental smoking behavior. Reach was measured by the proportion of students who signed a contract.

\section{Smoke free curriculum}

Context was measured by questions about alternative school based initiatives aiming at reducing tobacco use (school coordinators). Reach concerned all students attending year 7 to 9 . The teachers who delivered the smoke free classes answered questions about how many and which mandatory and optional exercises the classes completed. The dose received is measured by students' reports on number and quality of lessons received. Information on fidelity was also obtained from questions to the teachers. Their focus was whether the material was easy to work with, how the material performed, whether it was relevant for the students, how the students worked with the exercises, and whether the material suited the student's age level and level of knowledge.

Overall measures on environmental circumstances were obtained by questions to municipal coordinators regarding smoking policy and further initiatives in the municipality. Information on the procedure of recruitment for the study was determined by interviewing representatives from schools and municipalities participating in or declining to the study.

\section{Health economic evaluation}

School and municipal coordinators provided information about resources spent in connection with the study. This included time spent coordinating the study, preparing the $\mathrm{X}$ :IT lessons, as well as costs for lottery prizes, textbooks and other relevant material. Data provides the basis for health economic analysis of the X:IT intervention [40,41].

\section{Data collection}

For the baseline study, data collection among students at intervention and control schools was conducted at the beginning of year 7 . Follow-up data were collected at the end of year $7(1 \mathrm{FU})$, at the end of year $8(2 \mathrm{FU})$, and at the end of year 9 (3FU). We followed the students by using information on their name, birthday, class, and school. Students who changed school were omitted from the survey. Information from signed, smoke-free contracts was collected yearly. To gain information on the curricular activities, teachers were asked to complete questionnaires on conducted mandatory and optional classes. Also, we collected data among school and municipality coordinators at each follow-up (Table 2).

Students answered internet-based questionnaires in the classroom after a standardized instruction given by their teacher. The students were informed that participation was voluntary and their answers would be treated confidentially. Absentees were asked to answer questionnaires later, either at home or at school. At baseline, 4,161 students (93.1\%) were included in the final data file. At first follow-up, 3,764 students were included (84.9\%), and at the second follow-up, 3,269 (79.4\%) were included in the data files. Due to a conflict at the Danish labor market in Spring 2013 school teachers were locked out for a month. This resulted in a response rate among students at third follow-up at only $39.4 \%, \mathrm{n}=1,416$. Students were anonymized in the data file.

\section{Sustainability}

The X:IT study is intentionally rooted in the participating municipalities to acquire sustainability. Having a municipal study coordinator, who has been following the study for years, means that the capacity is built and maintained at the municipal level and that the study can easily be implemented at other schools.

At the end of first, second, and third year of the intervention, one-day study workshops were arranged for headteachers, municipal, and school coordinators. The workshops aimed at making participants share experiences and get inspiration for new methods of teaching as well as creating an environment for discussing or solving problems that may have occurred during the intervention the previous school year. An overview of the progress of the study was also provided.

\section{Statistical aspects \\ Power calculations}

The two Nordic studies, which the X:IT was inspired of, showed effect sizes between 30-50\%. The expected effect of the intervention is a $25 \%$ lower prevalence of 'current smokers' (smoke daily, weekly or more seldom) at age 15 in the intervention group compared to the control group, based on what was expected to be realistic in Denmark. Other necessary assumptions for the power calculations were that each school had on average three year 7 classes with an estimated average of 20 students per class. Within schools, students' smoking behavior is related. To estimate the intraclass correlation $(0.053$ for smoking weekly or more often among year 9 students), we used data from a large, nationally representative study among 15 -year olds with similar measures and design, "Health Behaviour in School-aged Children 2006" (HBSC) [42]. Using these assumptions and a power of $80 \%$, we needed 46 intervention schools and 46 control schools. Power calculations were conducted according to Donner \& Klar, [43]. 


\section{Data process and analyses}

Baseline data were imported into SAS version 9.2. Information from smoke-free contracts was merged with the baseline data. Variables on ethnic background were categorized into ethnic Danish, immigrants, and descendents of immigrants according to the definitions by Statistics Denmark. Variables on parental occupation were coded into six groups according to the Danish National Institute of Social Research: social class I (high) to V (low) and a group VI covering parents who were living on social welfare benefits. The students were categorized, according to the highest ranking parent, into three groups, family SEP I-II (high), III-IV (medium), and VVI (low).

Future analyses of first follow-up data will be conducted by means of multilevel logistic regression models. Furthermore, available case and intention-to-treat analyses will be performed; the latter with multiple imputation of missing data. In the analysis of second follow-up, a mixed model with repeated measures will be used. The random effects will handle the covariance within schools and classes. The fixed effects will include an interaction between time and the intervention indicator.

\section{Ethical issues}

There is no formal institution for ethical assessment and approval of questionnaire-based population studies in Denmark. When inviting the schools to participate, head teachers received written information about the study. Students and their parents were informed about the study. They were informed that participation was voluntary, that their information would be used for research purposes only and treated confidentially. Parents were informed of the possibility of having their child withdrawn from the data base. The study is registered at the Danish Data Protection Agency, ref: 2010-54-0930.

\section{Results}

\section{Process evaluation of the recruitment}

Semi-structured interviews with schools $(\mathrm{n}=3)$ and municipalities $(\mathrm{n}=5)$, who agreed to participate and schools $(\mathrm{n}=3)$, and municipalities $(\mathrm{n}=5)$ who declined to participate were performed to assess possible bias of participation. Generally, schools had three main reasons not to participate in the study. First, schools found that they lacked time or resources and could not engage in any more studies. Second, some schools had problems fulfilling the smoking restrictions of the study, especially for the teachers and therefore chose to decline the invitation. And third, for some schools, headteachers considered that putting smoking on the agenda seemed irrelevant because the students at the school had larger problems than those of smoking. Other schools believed they had few or no students who smoked. Smoking was, therefore, not considered a problem.

The main reason for municipalities not to participate in the study was a common worry that schools in the municipality were overloaded with work. Hence, the staff at the municipalities was reluctant to impose their schools further obligations. Some considered the study to be too large, carrying too many demands or the role as school coordinator to be overwhelming. Moreover, some argued that they could not ask their schools to be randomly selected to intervention and control schools. A number of municipalities prioritized alternative health promotion initiatives.

\section{Descriptive analyses of baseline data}

Ninety-seven schools from 17 municipalities entered random allocation. After allocation, three schools withdrew from the study leaving 51 schools as intervention schools and 43 schools as control schools. At baseline in September 2010, 4,468 year 7 students were eligible, of which 4,167 answered the baseline questionnaire (response rate $=93.3 \%$ ). We had to exclude six questionnaires due to sabotage, leaving 4,161 students in the final data file. Intervention schools and control schools did not differ by average number of year 7 students per school. Further, there were no differences in the gender composition or the composition of ethnic background, own smoking status or whether smoking control was enforced at school premises (Table 3). In the control group, more students were from high socioeconomic position compared to the intervention group, whereas, students from lower SEP families were equally distributed. More students at control schools saw teachers smoke daily and more parents in the intervention group were daily smokers. More students from intervention schools answered correctly to questions regarding knowledge of smoking and tobacco (Table 3).

\section{Discussion}

At the beginning of year 7, almost one fifth of the students in the X:IT study had tried to smoke, but only a small proportion of students smoked regularly. More than $60 \%$ of the students saw teachers smoke sometimes or every day during school hours. However, only one third of the students witnessed teachers checking student smoking on school premises. The prevalence of parental smokers was high (24.3\% to $31.1 \%)$ but are consistent with the prevalence among the adult Danish population of the relevant age group [44]. The X:IT baseline study thereby support earlier studies $[2,4]$ indicating a remaining need for interventions aimed at adolescent smoking in Denmark.

The X:IT intervention was inspired by the social influences approach. The intervention included three elements: 
Table 3 Description of the intervention and control group at baseline in the X:IT study

\begin{tabular}{|c|c|c|}
\hline & $\begin{array}{l}\text { Intervention } \\
\text { group }\end{array}$ & $\begin{array}{l}\text { Control } \\
\text { group }\end{array}$ \\
\hline \multicolumn{3}{|l|}{ Background factors } \\
\hline Number of schools (\%) & $51(54.3 \%)$ & $43(45.7 \%)$ \\
\hline Number of students (\%) & $2380(57.2 \%)$ & $1781(42.8 \%)$ \\
\hline $\begin{array}{l}\text { Average number of students pr. } \\
\text { school }\end{array}$ & 49.6 & 45.0 \\
\hline Sex (boys) (E) & $50.8 \%$ & $51.3 \%$ \\
\hline \multicolumn{3}{|l|}{ Ethnic background (A) } \\
\hline - Danes & $93.0 \%$ & $92.8 \%$ \\
\hline - Descendants & $4.1 \%$ & $4.2 \%$ \\
\hline • Immigrants & $2.9 \%$ & $3.1 \%$ \\
\hline \multicolumn{3}{|l|}{$\begin{array}{l}\text { Family socioeconomic position } \\
\text { (SEP) (C) }\end{array}$} \\
\hline • High & $33.6 \%$ & $38.7 \%$ \\
\hline - Medium & $48.4 \%$ & $42.8 \%$ \\
\hline$\cdot$ Low & $18.0 \%$ & $18.5 \%$ \\
\hline \multicolumn{3}{|l|}{ Intermediate factors: individual } \\
\hline $\begin{array}{l}\text { At least } 7 \text { out of } 13 \text { right answers on } \\
\text { knowledge questions (B) }\end{array}$ & $60.1 \%$ & $54.2 \%$ \\
\hline $\begin{array}{l}\text { Students should be allowed to smoke } \\
\text { outdoors on school premises (B) }\end{array}$ & $12.8 \%$ & $13.8 \%$ \\
\hline $\begin{array}{l}\text { Difficult to stay smoke-free if friends } \\
\text { smoke (F) }\end{array}$ & $59.9 \%$ & $60.2 \%$ \\
\hline $\begin{array}{l}\text { Willing to comply with parental } \\
\text { nonsmoking norms (D) }\end{array}$ & $90.7 \%$ & $90.0 \%$ \\
\hline \multicolumn{3}{|l|}{ Intermediate factors: context } \\
\hline Allowed to smoke at home (A) & $4.7 \%$ & $4.1 \%$ \\
\hline \multicolumn{3}{|l|}{ Parents daily smokers (C) } \\
\hline • Male & $31.1 \%$ & $27.9 \%$ \\
\hline - Female & $28.7 \%$ & $24.3 \%$ \\
\hline Best friend smokes (C) & $6.9 \%$ & $8.3 \%$ \\
\hline \multicolumn{3}{|l|}{ Teachers control smoking (G) } \\
\hline • Daily & $6.4 \%$ & $6.0 \%$ \\
\hline - Sometimes & $27.7 \%$ & $25.2 \%$ \\
\hline - Don't know & $47.1 \%$ & 49.3 \\
\hline \multicolumn{3}{|l|}{ See teachers smoke $(\mathrm{H})$} \\
\hline • Daily & $17.2 \%$ & $20.5 \%$ \\
\hline - Sometimes & $43.4 \%$ & $43.1 \%$ \\
\hline \multicolumn{3}{|l|}{ Outcome } \\
\hline Have ever tried smoking & $17.4 \%$ & $19.2 \%$ \\
\hline Monthly smokers & $3.0 \%$ & $4.2 \%$ \\
\hline
\end{tabular}

The letters $\mathrm{A}-\mathrm{H}$ refer to factors in the influential streams in Figure 1.

1) a strict anti-smoking school policy for students and teachers requering no visible smoking during school hours, 2) parental involvement including commitments for the student not to smoke, by signing contracts between students and a significant adult each year for three years as well as smoke-free dialogues, and 3) a 'smoke-free' curriculum including information about short and long-term health consequences of smoking, the benefits of staying smoke free, rates of smoking among Danish adults and adolescents, trainings on media and commercial influences, and skills training of competences to resist direct and indirect pressure to smoke.

A review study by Cuijpers [45] recommended the following ingredients to be included in order to achieve effective school-based drug prevention programs: 1) interactive delivery methods, 2) use of the social influence model, 3) focus on norms, and commitment and the intention not to use, 4) community interventions, e. g. family involvement, 5) use of peer leaders, and 6) inclusion of skills and practice in the use of refusal [45]. Apart from the use of peer leaders, the X:IT intervention included all the above mentioned ingredients.

$\mathrm{X}$ :IT was designed as a multi-modal program including initiatives within and beyond the school. The initiatives aim at strengthening and enforcing the rules for smoking at school premises beyond the scope of the Danish legislation. Also by including parents by way of signing smokefree contracts [24]. In a Cochrane review of school-based programs for preventing smoking, Thomas \& Perera [9] included randomized controlled trials and multi-modal programs, only. Nine out of thirteen studies drawing on social influence models found smoking prevalence to decline. The authors concluded that the evidence is still too weak to recommend which components should be included in a multimodal study for tobacco prevention [9]. Flay [46] criticized the rigid criteria used in the study for papers, in order to be included in the above mentioned Cochrane review. He claimed that many high quality studies were excluded from the review which limits the conclusions regarding effectiveness of school-based smoking prevention programs. Flay summarized results from metaanalyses, which had been more inclusive. He concluded that, school-based programs can have significant longterm effects if they: 1) use interactive social influences or social skills programs; 2 ) involve 15 or more lessons some of them encompassing year nine; and 3) produce substantial short-term effects [46].

Earlier antismoking studies, which focused on interventions aimed at adolescents from lower socioeconomic backgrounds, used social influences and social norms [47]. They also targeted the parents and recommended smoking prevention policies [48] as effective tools in preventing smoking among this group of adolescents. The X:IT intervention included all of these elements and consequently, created a basis for studying social inequality in smoking interventions.

Municipalities and schools participating in X:IT were evenly distributed across Denmark, which makes X:IT a 
nationwide study. All Danish municipalities and schools were invited to participate, but they had to register actively to join the study. This procedure may have introduced selection into the study. It may be schools with exceptional resources or specific engagement that have registered. On the other hand, smoking cluster in schools and is more prevalent among socially disadvantaged children. This could imply a stronger incentive for some schools to join the study. After registering for the study, schools were randomly allocated to either intervention or control.

Analyses did not reveal systematic differences between the intervention and control group. Randomization guarantees equal distribution of covariates across intervention and control groups. An observed imbalance can happen in any randomization, but a statistical significant distribution is unlikely to influence the effect of the intervention. Therefore, homogeneity should not be tested [49].

Power calculations took into account the multilevel structure of students nested in schools, which was the level of randomization. At baseline there was no significant attrition as more than ninety percent of the enrolled students answered the baseline questionnaires in both the intervention and the control schools.

All variables in the evaluation of the X:IT intervention were based on self-reported answers. Studies which examined the validity of adolescent self-reported smoking against biochemical measures found high sensitivity and specificity [50,51]. Even so, irregular smoking and timing of recent smoking influence the validity $[52,53]$. This indicates that questionnaires seem to provide reasonable estimates of the prevalence of adolescent smoking.

Measures in the X:IT study are mainly based on measures used in international validated studies, ESFA $[33,34]$, and HBSC $[37,54,55]$. Measures developed for the X:IT study have been tested for face validity in the pilot tests, but are not validated any further.

In the X:IT study, we want to examine the overall effect of the intervention. Previous intervention studies either did not measure the implementation of the interventions or measured implementation by use of single items $[56,57]$. The evaluation of X:IT measured several characteristics of the implementation [39] for each of the three main components of the intervention. Quantitative measures of the implementation were used. This will improve the ability to account for the degree of implementation of the intervention components when interpreting the study. We therby hope to add to the literature on implementation research of multi-component smoking intervention studies.

The literature on socially differential effects of smoking interventions is sparse, especially when investigating interventions among adolescents [58,59]. We want to use the X:IT evaluation to examine the socially differential effects of our intervention: Does it have equal effects among school children from both high and low socioeconomic positions or does it widen the socioeconomic gap in smoking behavior?

Finally, if the X:IT intervention proves to be effective and reasonable easy to implement; the strategy of anchoring the study in the Danish Cancer Society and in municipalities should increase its sustainability. Municipalities are in close contact with the schools and can offer the study to all schools in their district.

\section{Conclusions}

The X:IT intervention was a large, theory based, multicomponent school-based intervention evaluated by a randomized trial. Its aim is reducing adolescent smoking by $25 \%$ during a three-year intervention period. The intervention included three main components: 1) smokefree school premises, 2) parental involvement including smoke-free dialogues and signing of smoke-free contracts between student and parent, and 3) a curriculum addressing the issues of smoking. Meta-analyses have confirmed components to be efficient, also in a Nordic setting. The $\mathrm{X}$ :IT intervention filled a gap in Denmark. It was evaluated by a large, randomized trial with thorough measurements and performance of process-, effect-, and health economic evaluations of the study. We collect quantitative and qualitative data from students and study coordinators at schools and in municipalities at baseline, first, second, and third follow-up. We collect data meticulously on the implementation of the components. This enables us to add to the literature on quantitative measurements of degree of implementation. It also enables us to take into account the degree of implementation when estimating the effectiveness of the intervention. Furthermore, as the X:IT intervention was school-based, it has the potential to reach all children from both higher and lower socioeconomic backgrounds, a potential which provides the opportunity for studying social inequality in the effect of the smoking intervention.

\section{Competing interests}

The authors declare that they have no competing interests.

\section{Authors' contribution}

AA is the principal investigator of the evaluation of the X:IT intervention. AA coordinated the evaluation, acquisition of data, statistical analysis, and interpretation of data and drafted the manuscript. LSB participated in collection of data, procession of SAS data files, and revised the manuscript critically. LWR and LW are principal investigators of the development and design of the X:IT intervention. LWR contributed to the design, coordinated the implementation, and revised the manuscript critically. LW participated in developing the design, implementation of the study, developed the teaching materials, and revised the manuscript critically. PDJ participated in the design and implementation of the study, and revised the manuscript critically. MS participated in collection of data, procession of SAS data files, and revised the manuscript critically. PD participated in the design, and revised the manuscript critically. PDU acquired the funding, participated in 
the design of the evaluation, supervised the project group, and revised the manuscript critically. All authors read and approved the final manuscript.

\section{Authors' information}

The X:IT study is a collaboration between Centre for Intervention Research in Health Promotion and Disease Prevention and the Danish Cancer Society. Researchers from the Danish Cancer Society developed and implemented the project and researchers from Centre for Intervention Research conducted an independent and impartial scientific evaluation of the study. The X:IT study is registered at Current Controlled Trials ISRCTN77415416.

\section{Acknowledgements}

The X:IT project group would like to thank all participating schools, students, parents, teachers, and head teachers, as well as coordinators in the municipalities.

\section{Funding sources}

The X:IT study is part of Centre for Intervention Research in Health Promotion and Disease Prevention, National Institute of Public Health, University of Southern Denmark, Øster Farimagsgade 5A, 1353 Copenhagen, Denmark. The Centre is funded by Trygfonden and the Danish Cancer Society. The Danish Cancer Society funded the development and the running costs of the study. The evaluation of the X:IT study is funded by a five-year donation from Trygfonden including funding of AA, LSB and MS. PhD scholarship for LSB is Co-financed by University of Southern Denmark.

\section{Author details}

${ }^{1}$ National Institute of Public Health, University of Southern Denmark, Øster Farimagsgade 5A, 1353 Copenhagen, Denmark. ²Department for Prevention and Documentation, The Danish Cancer Society, Strandboulevarden 49, 2100 Copenhagen, Denmark.

Received: 1 February 2013 Accepted: 19 May 2014 Published: 28 May 2014

\section{References}

1. Juel K, Sørensen J, Brønnum-Hansen H: Risikofaktorer og Folkesundhed i Danmark (Risk Factors and Public Health in Denmark). Copenhagen, Denmark: National Institute of Public Health; 2006.

2. Nielsen GA, Ringgaard LW, Jensen PD, Møller TP, Nissen SB, Sindballe A, Falk J, Broholm K: Unges livsstil og dagligdag (Adolescent life style and daily living). Copenhagen: The Danish Cancer Society, Danish National Board of Health; 2006.

3. Nielsen LS, Andersen A, Rasmussen M: Tobaksrygning (Tobacco Smoking). In Skolebørnsundersøgelsen 2010 (Health Behaviour in School-Aged Children, Denmark 2010). Edited by Rasmussen M, Due P. Copenhagen: National Institute of Public Health, University of Southern Denmark; 2011:32-35.

4. Rasmussen M, Due P (Eds): Skolebørnsundersøgelsen 2010 (Health Behaviour in School-Aged Children Denmark 2010). Copenhagen: 2011.

5. Rasmussen M, Due P, Damsgaard MT, Holstein BE: Social inequality in adolescent daily smoking: has it changed over time? Scand J Public Health 2009, 37(3):287-294.

6. Krolner R, Damsgaard MT, Andersen A, Holstein BE, Due P: Social inequality in living conditions, health, well-being, and health behaviours. In Skolebørnsundersøgelsen 2010 (Health Behaviours in School-aged Children, Denmark 2010). Edited by Rasmussen M, Due P. Copenhagen: National Institute of Public Health, University of Southern Denmark; 2011:84-91.

7. Currie C, Molcho M, Boyce W, Holstein B, Torsheim T, Richter M: Researching health inequalities in adolescents: the development of the Health Behaviour in School-Aged Children (HBSC) family affluence scale. Soc Sci Med 2008, 66(6):1429-1436.

8. Rasmussen M, Due P, Andersen A, Krolner R, Holstein BE: Smoking trends in 11-15-year-olds from 1988 to 2006. Ugeskr Laeger 2008, 170(9):736-739.

9. School-based programmes for preventing smoking. Cochrane Database Syst Rev 2006, 19(3), CD001293.

10. Bruvold WH: A meta-analysis of adolescent smoking prevention programs. Am J Public Health 1993, 83(6):872-880.

11. Backinger $\mathrm{CL}$, Fagan $\mathrm{P}$, Matthews $\mathrm{E}$, Grana R: Adolescent and young adult tobacco prevention and cessation: current status and future directions. Tob Control 2003, 12(Suppl 4):IV46-IV53.
12. Sowden A, Arblaster L, Stead L: Community interventions for preventing smoking in young people. Cochrane Database Syst Rev 2003, 1, CD001291.

13. de Vries H, Dijk F, Wetzels J, Mudde A, Kremers S, Ariza C, Vitoria PD, Fielder A, Holm K, Janssen K, Lehtovuori R, Candel M: The European Smoking prevention Framework Approach (ESFA): effects after 24 and 30 months. Health Educ Res 2006, 21(1):116-132.

14. Vinther-Larsen M, Bendtsen $P$, Jørgensen MH, Grønbæk M: Evaluering af Undervisningsmaterialet Tackling (Evaluation of Tackling). Copenhagen: National Board of Health, Center for Prevention; 2008.

15. Flay BR, Petraitis J, Hu FB: The Theory of Triadic Influence; Preliminary Evidence Related to Alcohol and Tobacco use. In Alcohol and Tobacco: From Basic Science to Policy. Edited by Fertig JB, Allen JP. Bethesda, MD: National Institute on Alcohol Abuse and Alcoholism; 1995:37-57.

16. Johnston V, Westphal DW, Earnshzaw C, Thomas DP: Starting to smoke: a qualitative study of the experiences of Australian indigenous youth. BMC Public Health 2012, 12(1):963.

17. Lippke S, Nigg CR, Maddock JE: Health-promoting and health-risk behaviors: theory-driven analyses of multiple health behavior change in three international samples. Int J Behav Med 2012, 19(1):1-13.

18. Schofield PE, Pattison PE, Hill DJ, Borland R: Youth culture and smoking: integrating social group processes and individual cognitive processes in a model of health-related behaviours. J Health Psychol 2003, 8(3):291-306.

19. Klepp Kl, Perez-Rodrigo C, De Bourdeaudhuij I, Due PP, Elmadfa I, Haraldsdottir J, Konig J, Sjostrom M, Thorsdottir I, de Almeida MD V, Yngve A, Brug J: Promoting fruit and vegetable consumption among European schoolchildren: rationale, conceptualization and design of the pro children project. Ann Nutr Metab 2005, 49(4):212-220.

20. Emmons KM: Health Behaviors in a Social Context. In Social Epidemiology. Edited by Berkman LF, Kawachi I. New York: Oxford University Press; 2000:242-266

21. Bartholomew LK, Parcel GS, Kok G, Gottlieb NH: Planning health promotion programs. An intervention mapping approach. San Francisco: Jossey-Bass; 2006.

22. Moher D, Hopewell S, Schulz KF, Montori V, Gotzsche PC, Devereaux PJ, Elbourne D, Egger M, Altman DG: CONSORT 2010 explanation and elaboration: updated guidelines for reporting parallel group randomised trials. BMJ 2010, 340:c869. doi: 10.1136/bmj.c869.: p. c869.

23. Campbell MK, Piaggio G, Elbourne DR, Altman DG: Consort 2010 statement: extension to cluster randomised trials. BMJ 2012, 345:e5661.

24. Nilsson M, Stenlund $H$, Bergstrom $E$, Weinehall $L$, Janlert U: It takes two: reducing adolescent smoking uptake through sustainable adolescent-adult partnership. J Adolesc Health 2006, 39(6):880-886.

25. Josendal O, Aaro LE, Torsheim T, Rasbash J: Evaluation of the school-based smoking-prevention program "BE smokeFREE". Scand J Psychol 2005, 46(2):189-199.

26. Poulsen LH, Osler M, Roberts C, Due P, Damsgaard MT, Holstein BE: Exposure to teachers smoking and adolescent smoking behaviour: analysis of cross sectional data from Denmark. Tob Control 2002, 11(3):246-251.

27. Lipperman-Kreda S, Paschall MJ, Grube JW: Perceived enforcement of school tobacco policy and adolescents' cigarette smoking. Prev Med 2009, 48(6):562-566.

28. Adams ML, Jason LA, Pokorny S, Hunt Y: The relationship between school policies and youth tobacco use. J Sch Health 2009, 79(1):17-23. quiz 41-3.

29. Jackson C, Henriksen L: Do as I say: parent smoking, antismoking socialization, and smoking onset among children. Addict Behav 1997, 22(1):107-114.

30. Donaldson SI, Sussman S, MacKinnon DP, Severson HH, Glynn T, Murray DM, Stone EJ: Drug abuse prevention programming; do we know what works? Am Behav Sci 1996, 39:868-883.

31. Wold B, Currie C, Lund M: Control of Adolescent Smoking (the CAS Study) 1997/1998. Technical Report on Surveys of 15 Year-Olds in Nine European Countries. Bergen; Norway: Bergen University; 2000.

32. Wold B, Torsheim T, Currie C, Roberts C: National and school policies on restrictions of teacher smoking: a multilevel analysis of student exposure to teacher smoking in seven European countries. Health Educ Res 2004, 19(3):217-226.

33. de Vries H, Mudde A, Kremers S, Wetzels J, Uiters E, Ariza C, Vitoria PD, Fielder A, Holm K, Janssen K, Lehtovuori R, Candel M: The European Smoking Prevention Framework Approach (ESFA): short-term effects. Health Educ Res 2003, 18(6):649-663. 
34. De Vries $H$, Mudde AN: Predicting stage transitions for smoking cessation applying the attitude-social influence-efficacy model. Psychol Health 1998, 13:17.

35. Griebler R, Molcho M, Samdal O, Inchley J, Dür W, Currie C (Eds): Health Behaviour in School-Aged Children: a World Health Organization CrossNational Study. Research Protocol for the 2009/2010 Survey. Vienna: LBIHPR \& Edinburgh: CAHRU; 2010. Available from http://www.hbsc.org.

36. Kremers SP, Mudde AN, De Vries H: Subtypes within the precontemplation stage of adolescent smoking acquisition. Addict Behav 2001, 26(2):237-251.

37. Nordahl H, Krolner R, Pall G, Currie C, Andersen A: Measurement of ethnic background in cross-national school surveys: agreement between students' and parents' responses. J Adolesc Health 2011, 49(3):272-277.

38. Schwarzer R: Measurement of Perceived Self-Efficacy. Psychometric Scales for Cross-Cultural Research. Berlin, Germany: Freie Universität Berlin; 1993.

39. Steckler A, Linnan L (Eds): Process Evaluation for Public Health Interventions and Research. San Francisco: Jossey-Bass; 2002.

40. Flay BR, Biglan A, Boruch RF, Castro FG, Gottfredson D, Kellam S, Moscicki EK, Schinke S, Valentine JC, Ji P: Standards of evidence: criteria for efficacy, effectiveness and dissemination. Prev Sci 2005, 6(3):151-175.

41. Coast J: Is economic evaluation in touch with society's health values? BMJ 2004, 329(7476):1233-1236.

42. Rasmussen M, Due P: Skolebørnsundersøgelsen 2006 (Health Behaviour in School-Aged Children 2006). Copenhagen: Institute of Public Health, University of Copenhagen; 2007.

43. Donner A, Klar N: Statistical considerations in the design and analysis of community intervention trials. J Clin Epidemiol 1996, 49(4):435-439.

44. Christensen Al, Ekholm O, Davidsen M, Juel K: Sundhed og Sygelighed i Danmark 2010 \& Udviklingen Siden 1987 (Health and Sickness in Denmark 2010 \& Development Since 1987). Copenhagen, Denmark: National Institute of Public Health, University of Southern Denmark; 2012.

45. Cuijpers P: Effective ingredients of school-based drug prevention programs. A systematic review. Addict Behav 2002, 27(6):1009-1023.

46. Flay BR: The promise of long-term effectiveness of school-based smoking prevention programs: a critical review of reviews. Tob Induc Dis 2009, 5(1):7.

47. Crone MR, Reijneveld SA, Willemsen MC, van Leerdam FJ, Spruijt RD, Sing RA: Prevention of smoking in adolescents with lower education: a school based intervention study. J Epidemiol Community Health 2003, 57(9):675-680.

48. De Vries H: Socio-economic differences in smoking: Dutch adolescents' beliefs and behaviour. Soc Sci Med 1995, 41(3):419-424.

49. Senn SJ: Covariate imbalance and random allocation in clinical trials. Stat Med 1989, 8(4):467-475.

50. Kentala J, Utriainen P, Pahkala K, Mattila K: Verification of adolescent self-reported smoking. Addict Behav 2004, 29(2):405-411.

51. Post A, Gilljam H, Rosendahl I, Meurling L, Bremberg S, Galanti MR: Validity of self reports in a cohort of Swedish adolescent smokers and smokeless tobacco (snus) users. Tob Control 2005, 14(2):114-117.

52. Dolcini MM, Adler NE, Lee P, Bauman KE: An assessment of the validity of adolescent self-reported smoking using three biological indicators. Nicotine Tob Res 2003, 5(4):473-483.

53. Caraballo RS, Giovino GA, Pechacek TF: Self-reported cigarette smoking vs. serum cotinine among U.S. adolescents. Nicotine Tob Res 2004, 6(1):19-25.

54. Roberts C, Freeman J, Samdal O, Schnohr CW, de Looze ME, Nic Gabhainn S, lannotti R, Rasmussen M: The Health Behaviour in School-aged Children (HBSC) study: methodological developments and current tensions. Int J Public Health 2009, 54(Suppl 2):140-150.

55. Andersen A, Krolner R, Currie C, Dallago L, Due P, Richter M, Orkenyi A Holstein BE: High agreement on family affluence between children's and parents' reports: international study of 11-year-old children. J Epidemiol Community Health 2008, 62(12):1092-1094.

56. Dane $\mathrm{AV}$, Schneider $\mathrm{BH}$ : Program integrity in primary and early secondary prevention: are implementation effects out of control? Clin Psychol Rev 1998, 18(1):23-45.

57. Dusenbury L, Brannigan R, Falco M, Hansen WB: A review of research on fidelity of implementation: implications for drug abuse prevention in school settings. Health Educ Res 2003, 18(2):237-256.

58. Thomas S, Fayter D, Misso K, Ogilvie D, Petticrew M, Sowden A, Whitehead $M$, Worthy G: Population tobacco control interventions and their effects on social inequalities in smoking: systematic review. Tob Control 2008, 17(4):230-237.

59. Niederdeppe J, Kuang X, Crock B, Skelton A: Media campaigns to promote smoking cessation among socioeconomically disadvantaged populations: what do we know, what do we need to learn, and what should we do now? Soc Sci Med 2008, 67(9):1343-1355.

doi:10.1186/1471-2458-14-518

Cite this article as: Andersen et al:: Design of a school-based randomized trial to reduce smoking among 13 to 15 -year olds, the X:IT study.

BMC Public Health 2014 14:518.

\section{Submit your next manuscript to BioMed Central and take full advantage of:}

- Convenient online submission

- Thorough peer review

- No space constraints or color figure charges

- Immediate publication on acceptance

- Inclusion in PubMed, CAS, Scopus and Google Scholar

- Research which is freely available for redistribution 